\title{
Design Optimization of a Concrete Face Rock-Fill Dam by Using Genetic Algorithm
}

\author{
Yanlong Li, Jing Wang, and Zengguang Xu \\ State Key Laboratory Base of Eco-Hydraulic Engineering in Arid Area, Xian University of Technology, Xian 710048, China \\ Correspondence should be addressed to Yanlong Li; liyanlong@xaut.edu.cn and Zengguang Xu; xuzengguang@xaut.edu.cn
}

Received 20 November 2015; Accepted 21 February 2016

Academic Editor: Filippo Ubertini

Copyright (C) 2016 Yanlong Li et al. This is an open access article distributed under the Creative Commons Attribution License, which permits unrestricted use, distribution, and reproduction in any medium, provided the original work is properly cited.

\begin{abstract}
This paper combined with the adaptive principle to improve the genetic algorithms (GA) and applied it to optimal design of the shape of the concrete face rock-fill dam (CFRD). Based on the improved GA, a mathematical model was established for the design optimization of CFRD. CFRD utilizes dam cost as objective function and dam slope and geometries of the dam material partition as design variables. Dam stability, stress, displacement, and stress level are used as the main condition constraints. The calculation procedures were prepared, and the GA was used to optimize the design of Jishixia CFRD. Results show that the GA could solve the global optimal solution problem of complex optimization design, such as the high degree of nonlinearity and the recessiveness of constraint conditions, and using the GA to optimize the CFRD design can reduce the quantities of projects and engineering safety costs.
\end{abstract}

\section{Introduction}

The objective function and constraint conditions for the design optimization of a concrete face rock-fill dam (CFRD) are nonlinear functions of design variables. Constraint conditions are implicit functions of design variables; however, deriving these constraint conditions is difficult [1]. The current design optimization methods for CFRD mainly focus on mathematical programming and criterion methods, which include the full stress criterion, complex method, and penalty function method. These methods have several limitations, such as slow convergence and low efficiency [2].

Holland [3] first proposed a genetic algorithm (GA) that has main features operating directly on object structures. The continuity of the GA derivatives and functions has no limitations. GA has inherent implicit parallelism and good global optimization capability. GA also uses the probability optimization method, which can automatically access and guide the optimized search space, can adjust the search direction adaptively, and does not require rule determination.

Ackley [4] proposed a strategy called "stochastic iterated genetic hill-climbing" (SIGH) that uses a complex probability election mechanism composed of $M$ "voters" to decide the value of the new individual (" $M$ " refers to the size of groups).
Experimental results show that four of the six test functions of the SIGH with single-point crossover, namely, the uniform crossover neural GA, exhibited better performance than that of other algorithms. Overall, the SIGH is more competitive in the speed of solving compared with many existing algorithms. In another study, Whitley et al. [5] proposed a crossover operator on the basis of the cross field. This crossover operator is specifically for crossing individuals by using numbers to represent genes. The application of the crossover operator to the travelling salesman problem (TSP) has been verified by experiments [6].

Bersini and Seront [7] combined GA with the simplex method and formed a single operation called "multi-parent crossover operator." This operator produces new individuals through two maternal individuals and an additional individual. The cross results are consistent with those of three individuals with elections. Three crossover operators have been compared with the subpoint crossover and uniform crossover operators. Results show that the three crossover operators have better performance than that of the other two operators.

Many experts and scholars in China have improved the crossover operator of GA. For instance, Dai et al. [8] presented an algorithm of pattern extraction approach to 
the mutation mechanism for Genetic Algorithm. The direction of the mutation of individual is guided by two consecutive evolution directions of the individual, such as the mutation probability, different mutation operators to search for a variable space, and migration of operators among populations to exchange genetic information and solve the problems of the classical GA converging to a local optimum value. Zhao et al. [9] proposed the building-block-coded parallel GA, which is encoded by gene block. This GA is utilized when the simple GA is used on large-scale combinatorial optimization problems with low searching efficiency. This method is based on the coarse-grained parallel GA and aims to identify possible gene block among the chromosome population. The identified gene block is used as a new gene block to recode the chromosome and to generate chromosomes with shorter lengths. The recoded chromosome groups are then used as the initial population that progresses to the next round of evolution. Jiang [10] utilized a flexible strategy to maintain the diversity of groups for parallel GA to solve the TSP, which enables the algorithm to cross the local convergence obstacles and reach the evolution of the global optimum direction. Zhang et al. [11] constructed the analysis and inverse analysis system of temperature stress simulation. The system realizes the automation and intellectualization of complex data analysis and preparation work in simulation process and complex data adjustment in the inverse analysis process, which can facilitate the realtime tracking simulation and feedback analysis of concrete temperature stress in construction process. Gu et al. [12] proposed a new method to inverse the actual initial zoning deformation modulus and to determine the inversion objective function for the actual zoning deformation modulus, based on the dam displacement measured data and finite element calculation results. Furthermore, based on the chaos genetic optimization algorithm, the inversion method for zoning deformation modulus of dam, dam foundation, and reservoir basin is proposed. Combined with the project case, the feasibility and validity of the proposed method are verified. The internal relation between concrete dam crack behavior abnormality and statistical change point theory is deeply analyzed by $\mathrm{Li}$ et al. [13] from the model structure instability of parametric statistical model and change of sequence distribution law of nonparametric statistical model. And the nonparametric change point diagnosis method of concrete dam crack behavior abnormality is used in the actual project, demonstrating the effectiveness and scientific reasonableness of the method established. Rezaiee-Pajand and Tavakoli [14] introduced an efficient procedure for crack detection in concrete gravity dams. A genetic algorithm and finite element modeling are employed to perform the optimization tasks. Moreover, a genetic algorithm approach for crack identification is proposed, which can identify the location and magnitude of cracks in concrete gravity dams. By minimizing the difference between the analytical responses given by Rezaiee-Pajand and Tavakoli's element and the measured ones, the genetic algorithm identifies the crack.

GA has achieved great success in practical applications. However, on a biological basis, the GA has mathematical flaws $[15,16]$. A number of defects exist when GA is used in calculations, which include slow speed and immature convergence. Moreover, GA encounters problems on search efficiency and time [17-19]. These deficiencies seriously impede the promotion and application of GA. In this paper, GA was improved based on adaptive principle [20] and applied for the design optimization of CFRD.

This paper combined with the adaptive principle, based on the genetic algorithm, and applied it to optimal design of the shape of the concrete face rock-fill dam.

\section{Mathematical Models for the Design Optimization of CFRD}

2.1. Design Variables. In the cross-sectional design of CFRD, the dam height, the width of the dam crest, and other data are unchanged parameters that are determined in accordance with the project planning requirements. However, these parameters are generally not considered as design variables. The angle of the upstream dam slope $x_{1}$, the angle between the dam material boundaries and the horizontal direction $x_{2}$, and the angle of the downstream dam slope $x_{3}$ are considered as design variables of the CFRD cross section.

2.2. Objective Function. The CFRD sections consist of different material partitions. After considering different comprehensive factors, such as exploitation, transportation, and construction, the unit price of volume formed by different materials was determined. For the unit length section, the unit price of each feed zone was compared. A material was selected, and the unit price of the material was assumed as 1.0. The ratio of the unit price of the selected material to that of the price of other materials is price proportional, which is denoted as $C_{i}$. The objective function can be expressed as follows:

$$
f=\sum\left(C_{i} \times S_{i}\right)
$$

where $f$ is the project cost of the dam and $S_{i}$ is the area of the material in the dam cross section.

2.3. Constraint Conditions. The water pressure on the upstream panel can be directly determined by considering the structure and state of workability of CFRD. Thus, the sliding force produced by the dead weight of the dam and the water pressure on the panel significantly outweighs the horizontal thrust. However, this phenomenon does not produce an integral sliding problem. During design optimization, the constraint conditions take the following forms:

(1) Geometric constraint conditions $x_{l} \leq x \leq x_{u}$.

(2) Maximum stress constraint conditions $\sigma \leq[\sigma]$.

(3) Preventive plastic shear failure conditions $S_{L} \leq\left[S_{L}\right]$.

(4) Dam slope stability constraint conditions $F_{s} \geq\left[F_{s}\right]$.

$x_{l}$ is the lower limit of variables, $x_{u}$ is the upper limit of variables, $\sigma$ is the stress, $S_{L}$ is the stress level, and $F_{s}$ is the safety coefficient of the dam slope stability. 


\section{Improved GA with the Adaptive Principle}

As a kind of stochastic optimization method, the basic GA also have some shortcomings, like the weak local searching ability, the nonhigh optimization accuracy, premature convergence, and many other shortcomings. In order to make up for these deficiencies, this paper combined with the adaptive principle to improve the GA and applied it to optimal design of the shape of the concrete face rock-fill dam; the specific improvement process is as follows.

3.1. Parameter Coding. Coding is the most important issue concerning GA application. Several types of coding methods have been proposed, which can be divided into three categories: binary coding method, floating-point coding method, and symbol coding method. The optimization of CFRD has many design variables. If the binary coding method is used, the coding strings will be long, and the coding and decoding processes will be complex, which may affect the computational efficiency. Therefore, the simple floating-point coding with high accuracy and simple process was chosen for this study.

3.2. Generation of the Initial Group. To solve the constrained initial group, an initial feasible individual $x_{1}$ can be randomly generated if the individual is a boundary point of a feasible region. The regeneration is conducted until the initial feasible individual $x_{1}$ is produced, which is the interior point of the feasible region. Thus, another initial individual $x_{2}$ can be randomly generated, as expressed in the following equation:

$$
x_{2}=a+r_{2} \times(b-a),
$$

where $a=\left(a_{1}, a_{2}, \ldots, a_{n}\right)^{T}, r_{2}=\left(r_{21}, r_{22}, \ldots, r_{2 n}\right)^{T}$, and $b=$ $\left(b_{1}, b_{2}, \ldots, b_{n}\right)^{T}$.

We need to determine whether the individual $x_{2}$, which is generated by (2), can satisfy the constraint conditions. If the condition is met, then a new initial individual $x_{3}$ will be generated. Otherwise, the value of $x_{2}$ continually approximates that of $x_{1}$; that is, an iteration will be conducted by using the following equation:

$$
x_{2}=x_{1}+\alpha\left(x_{2}-x_{1}\right),
$$

where $\alpha$ is a coefficient greater than 0 but less than 1 and is generally taken as 0.5 .

$x_{2}$ can become a feasible individual after the constant iterations. The individual $x_{3}$ can be generated by using the same method as that of $x_{2} . x_{3}$ can be converted into an initial feasible individual; the iteration continues until $m$ individuals are generated.

\subsection{Treatment of Fitness Function and Constraint Conditions.} To meet the requirements of GA, the fitness function should be nonnegative and the problems should be maximum optimization problems. In the optimization problem of CFRD, the upper and lower limit constraints of design variables are considered during coding. The other constraint conditions are used to deal with the penalty function. Therefore, the objective function in the optimization problem of CFRD is expressed as follows:

$$
F(x)= \begin{cases}C_{\max }-f(x) & f(x)<C_{\max } \\ 0 & f(x) \geq C_{\max }\end{cases}
$$

where $C_{\max }$ is a large number greater than $F(x)$ and is taken as 50000 .

\subsection{Genetic Operation}

3.4.1. Selection Operation. The basic idea of selection proportion is that the probability of each individual being selected is proportional to the degree of its fitness. Individuals with a higher degree of fitness have greater probability of passing their characteristics to the next generation.

3.4.2. Crossover Operation. The arithmetic crossover operator was used; that is, two individuals were randomly selected and then combined linearly to generate two new individuals:

$$
\begin{aligned}
& A=\gamma_{0} X_{j 1}+\left(1-\gamma_{0}\right) X_{j 2}, \\
& B=\gamma_{0} X_{j 2}+\left(1-\gamma_{0}\right) X_{j 2},
\end{aligned}
$$

where $\gamma_{0}$ is a random number uniformly distributed between 0 and 1 . Consider

$$
P_{c}= \begin{cases}k_{13} & \left|f^{\prime}-f_{\max }\right| \leq v_{\text {fix }} \\ \frac{k_{1}\left(f_{\max }-f^{\prime}\right)}{f_{\max }-f_{\text {ave }}} & f^{\prime} \geq f_{\text {ave }} \\ k_{3} & f^{\prime}<f_{\text {ave }} .\end{cases}
$$

Here, $f_{\max }$ is the maximum fitness value among groups, $f$ is the fitness value of the variation individual, $f_{\text {ave }}$ is the average fitness value of the groups of each generation, and $f^{\prime}$ is the larger fitness value between two individuals conducting the interlace operation.

To improve the quality of crossover, the crossover probability was generated by using (6) and $P_{c}$ was controlled by the degree of evolution. Here, $k_{1}=1, k_{3}=0.9, k_{13}=0.5$, and $v_{\text {fix }}=$ 0.001 .

3.4.3. Mutation Operation. A nonuniform mutation operation was used; that is, every variable can be mutated independently according to the following equation:

$$
X_{i}= \begin{cases}\left(X_{i \max }-X_{i}\right)\left(1-r^{(1-t / T)^{B}}\right) & \mathrm{rad}=0 \\ \left(X_{i}-X_{i \min }\right)\left(1-r^{(1-t / T)^{B}}\right) & \mathrm{rad}=1,\end{cases}
$$

where $t$ is algebra of evolution; $r$ is a random number between 0 and $1 ; T$ is the maximum evolution algebra; $B$ is the system parameter, which is generally taken as 2 .

To improve the quality of mutation, the mutation probability was generated by using (8); that is, $P_{m}$ was controlled by 
the degree of evolution. Here, $k_{2}=0.5, k_{4}=0.065, k_{24}=0.07$, and $v_{\text {fix }}=0.001$. Consider

$$
P_{m}= \begin{cases}k_{24} & \left|f^{\prime}-f_{\max }\right| \leq v_{\text {fix }} \\ \frac{k_{2}\left(f_{\max }-f^{\prime}\right)}{f_{\max }-f_{\text {ave }}} & f^{\prime} \geq f_{\text {ave }} \\ k_{4} & f^{\prime}<f_{\text {ave }} .\end{cases}
$$

\section{Optimal Design Program of CFRD Based on the Improved GA}

4.1. Overall Design of the Program Structure. The program includes three modules, namely, the module of inputting the original data, the module of calculating the optimal design, and the module of outputting the results. The entire program is written by using FORTRAN. The initial data are read in the form of documents and stored in the form of program variables. The final optimization results can be obtained through cycle calculation and the output in the form of files.

\subsection{Function Design of Each Program Module}

4.2.1. Module of Inputting the Original Data. The original data can be divided into three parts. The first part is used to calculate the geometry of CFRD, which includes two aspects, (1) the operation parameters of genetic operation, which include the size of group $M$ and the maximum time of iterations $T$, and (2) the structural dimensions of CFRD, which include the thickness of panels and cushions, the level of thickness of transition layers, the dam height, and the water level. The second part is used to calculate the stability of the dam slope, which includes the physical and mechanical indexes of dam materials, the upstream and downstream water levels during the construction period, and the earthquake coefficient. The third part is used to calculate the stress and deformation of the dam, which included the load series, the number of structure partitions, and the calculation parameters of Duncan-Chang stress-dependent bulk modulus (E-B) model of each dam material.

4.2.2. Module of the Optimal Design Calculation. The module of the optimal design calculation is the core of the entire program. Given that CFRD has many material partitions, the calculation of the structural reanalysis requires a significant amount of work. Therefore, when writing the program that calculates the optimal design of CFRD, the calculations of slope stability and dam stress deformation must be treated as subprograms, whereas the improved GA must be treated as the main program.

(1) Calculation of Slope Stability. The calculation program of the slope stability utilizes the Bishop method for the analysis of the circular-slip surface. This program can be used not only in analyzing the stability of any designated slip-out point and arbitrary designated sliding arc but also in determining the stability of all possible slide-out points as artificially designated density interpolates between any two slide-out points of the dam slope.

(2) Calculation of Stress Deformation. The nonlinear finite element method is used to analyze the characteristics of the dam stress deformation. The dam materials utilize the nonlinear Duncan-Chang E-B constitutive model during simulation. The simulation construction process calculates and applies loads layer by layer. The filling layer and the filling soil are calculated; however, the resulting displacement and strain are changed to zero, thus leaving the stresses in the equation. The load increment should have the smallest possible value to reflect the nonlinear characteristics of the dam material.

(3) Calculation of Genetic Manipulation. The module of genetic manipulation is the main program of the improved GA optimization program. The genetic manipulation includes selection operation, crossover operation, and mutation operation. Figure 1 shows the calculation flow chart.

4.2.3. Module of Outputting Results. The output data of this optimization program are as follows:

(1) The optimal solution and the value of its objective function, in which the solution has to meet the constraint condition, include stability and stress deformation.

(2) The safety factor of slope stability, which meets the constraint condition and is under the specified calculation condition, corresponds to the optimal solution.

(3) The calculation results of stress and deformation on the dam and panel, in which the results are under the specified calculation condition, must correspond to the optimal solution and must meet the constraint condition. The horizontal displacement is positive when it moves toward the dam downstream, whereas the vertical displacement is positive when it moves toward the dam upstream. Stress is positive when it is compressive and negative when it is tensile.

\section{Example Analyses}

5.1. Project Profile. Jishixia CFRD is a large (II) type of hydraulic complex project, in which the dam is a singlelevel building with crest elevation of $1861 \mathrm{~m}$, crest width of $10 \mathrm{~m}$, and maximum dam height of $100 \mathrm{~m}$. The minimum excavation height of the toe slab is $1761 \mathrm{~m}$, the slope ratio of the upstream dam slope is $1: 1.4$, the comprehensive slope ratio of the downstream dam slope is $1: 1.71$, the normal high water level is $1856 \mathrm{~m}$, and the corresponding downstream water level is $1783.26 \mathrm{~m}$. The grade zones of material in the dam from upstream to downstream consist of the following: concrete face slab, cushion zone, transition zone, main rockfill area, and downstream rock-fill zone. Figure 2 shows the diagram of the dam design optimization variables. 


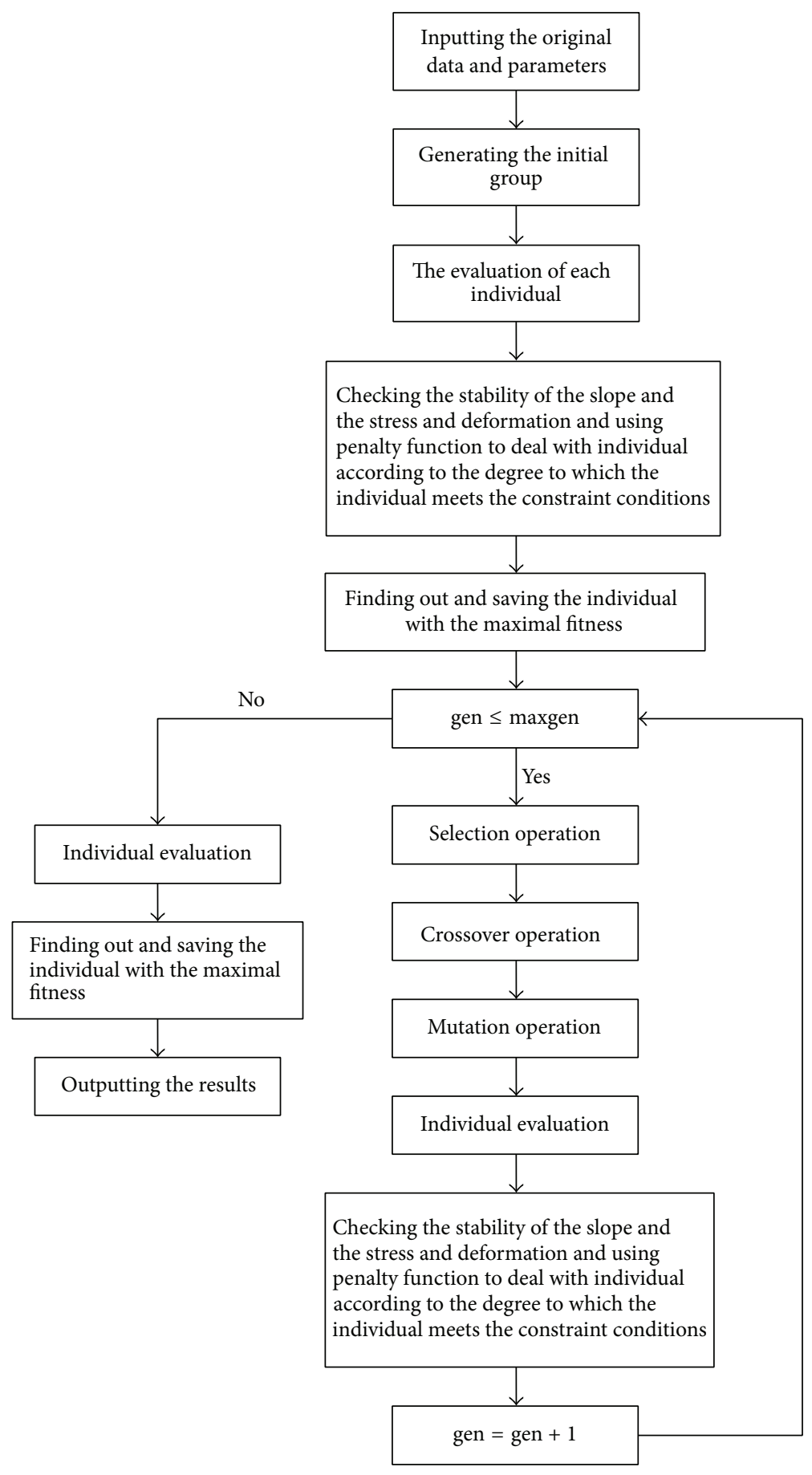

FIgUre 1: Module flow chart of GA.

5.2. Basic Information. The comprehensive parities of the dam materials include the downstream rock-fills, main rockfills, transition materials, cushion material, and panel concrete, with ratio of $1: 1.42: 1.81: 2.13: 18.68$.

Geometric Constraints. Consider $2.486 \leq x_{1} \leq 2.61, x_{1} \leq x_{2} \leq$ $x_{3}$, and $0.532 \leq x_{3} \leq 0.656$.
Condition Constraints. The allowable stability safety factor is $\left[F_{s}\right]=1.35$, the allowable tensile stress is $\left[\sigma_{L}\right]=1.0 \mathrm{MPa}$, the allowable pressure stress is $\left[\sigma_{c}\right]=10.0 \mathrm{MPa}$, and the maximum allowable stress level is $\left[S_{L}\right]=1.0$.

The geometric constraints were selected based on the experience of completed domestic and international constructions. The safety factor of stability was selected based on 
TABLE 1: Material parameters simulated by using the Duncan-Chang E-B model.

\begin{tabular}{lcccccccccc}
\hline Material & $\rho /\left(\mathrm{kg} \cdot \mathrm{m}^{-3}\right)$ & $\varphi /\left(^{\circ}\right)$ & $\Delta \varphi /\left(^{\circ}\right)$ & $C$ & $K$ & $K_{\mathrm{ur}}$ & $K_{b}$ & $n$ & $R_{f}$ & $m$ \\
\hline Cushion & 2200 & 50.6 & 7 & 0 & 400 & 800 & 520 & 0.35 & 0.78 & 0.22 \\
Transition layer & 2180 & 52.5 & 10 & 0 & 850 & 1700 & 550 & 0.3 & 0.77 & 0.20 \\
Main rock-fill zone & 2135 & 56.5 & 13 & 0 & 1070 & 1300 & 260 & 0.36 & 0.82 & 0.40 \\
Secondary rock-fill zone & 2121 & 56.5 & 11 & 0 & 310 & 700 & 110 & 0.39 & 0.59 & 0.30 \\
\hline
\end{tabular}

TABLE 2: Comparative results of the initial design and the optimal program.

\begin{tabular}{|c|c|c|c|c|c|}
\hline \multirow{2}{*}{ Program } & \multirow{2}{*}{ Iterative step } & \multicolumn{3}{|c|}{ Design variables/rad } & \multirow{2}{*}{$\begin{array}{c}\text { Objective function } \\
\qquad F(x)\end{array}$} \\
\hline & & $x_{1}$ & $x_{2}$ & $x_{3}$ & \\
\hline Initial design & - & 2.521 & 1.373 & 0.620 & 23946.91 \\
\hline Complex algorithm & 535 & 2.500 & 1.560 & 0.656 & 22819.05 \\
\hline GA & 157 & 2.497 & 1.560 & 0.653 & 22803.83 \\
\hline
\end{tabular}

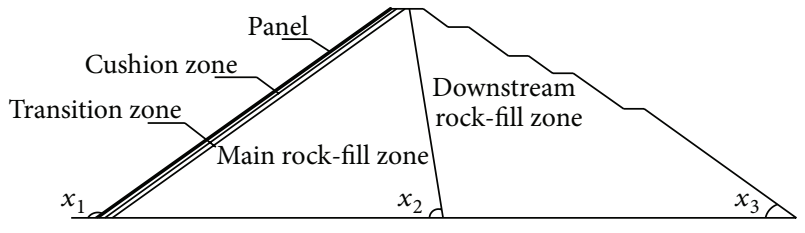

FIGURE 2: Diagram of the optimal design variables.

the relevant provisions of China in Design Code for Concrete Face Rock-Fill Dams (SL228-98).

Structure analysis must be performed to establish the condition constraints. Dam slope stability analysis, which is conducted by using the Swedish slice method and the finite element analysis of CFRD deformation and stress, should also be conducted. The condition for water storage calculation for the upstream water level is $1856 \mathrm{~m}$, whereas the condition for the downstream water level is $1783.26 \mathrm{~m}$.

The linear elastic constitutive model was used to simulate the concrete face. $\varepsilon$ (elastic modulus) $=2 \times 10^{10} \mathrm{pa}, \mu$ $($ Poisson's ratio $)=0.167$, and $\rho$ (density) $=2450 \mathrm{~kg} / \mathrm{m}^{3}$. The Duncan-Chang E-B constitutive model was used to simulate the dam materials, as shown in Table 1.

\subsection{Optimizing Results}

5.3.1. Analysis of the Optimal Program. The paper uses the genetic algorithm and the complex algorithm to conduct the optimizing design of Jishixia concrete face rock-fill dam, respectively, and the calculation results of these two optimizing design programs are compared with the initial design by listing. The design variables and the results of objective function of the design with genetic algorithm and complex algorithm and the initial design are compared in Table 2. The comparative figure about optimal program with genetic algorithm and the initial design are shown in Figure 3.

(1) Table 2 and Figure 3 show that, after optimization, the upstream and downstream slopes of the dam became steeper, the angle of the upstream slope of the dam decreased from $2.521 \mathrm{rad}$ to $2.497 \mathrm{rad}$, and the angle of the downstream

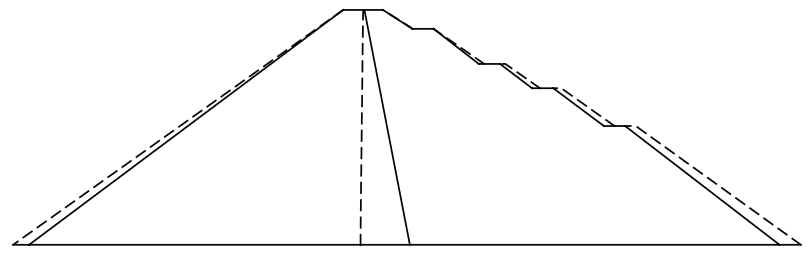

- Improved GA

- - Initial design

FIgURE 3: Comparison of the dam section between the initial design and the GA.

slope of the dam increased from $0.620 \mathrm{rad}$ to $0.653 \mathrm{rad}$. Consequently, the area of the dam section decreased, thus decreasing the dam cost. The angle between the dam material boundaries and the horizontal direction increased from $1.373 \mathrm{rad}$ to $1.560 \mathrm{rad}$. This increase in angle increased the content of the downstream rock-fill, thereby reducing the dam cost. Compared with the initial design scheme, the dam cost was reduced by $4.8 \%$ after optimization.

(2) From the comparison optimized results of the complex algorithm and the genetic algorithm, it can be seen that the two optimal results of optimization method are basically the same; it is also shown that the two methods are suitable for the optimization design of the face rock-fill dam. The generation number of the complex algorithm converging to the optimal solution is 535 . However, the generation number of genetic algorithm converging to the optimal solution is 157; the consumed time of genetic algorithm is below one-third of complex algorithm. Thereby, the genetic algorithm is more efficient and speedy.

(3) The convergence process for objective function according to generation number is reflected in Figure 4; we can see that the objective function decreases rapidly and then the speed of decrease is reduced and gradually comes to stability in the top 15 generation numbers. Figures 5-7 show the changing process for three parameters of $x_{1}, x_{2}$, and $x_{3}$ according to generation number. The trend of parameter $x_{1}$ and objective function are basically the same in Figure 5 . We can see that parameter $x_{2}$ and parameter $x_{3}$ rise rapidly 
TABLE 3: Comparative program results before and after optimization.

\begin{tabular}{|c|c|c|c|c|c|c|}
\hline \multirow{2}{*}{ Program } & \multirow{2}{*}{ Conditions } & \multicolumn{5}{|c|}{ Behavior indicators } \\
\hline & & $\sigma_{L} / \mathrm{MPa}$ & $\sigma_{c} / \mathrm{MPa}$ & $S_{L}$ & $\delta / \mathrm{m}$ & $F_{s}$ \\
\hline \multirow{2}{*}{ Before optimization } & Completion period & 0.43 & 1.69 & 0.68 & 0.11 & \multirow{2}{*}{1.79} \\
\hline & Impounding period & 0.50 & 1.84 & 0.58 & 0.22 & \\
\hline \multirow{2}{*}{ After optimization } & Completion period & 0.43 & 1.72 & 0.83 & 0.16 & \multirow{2}{*}{1.35} \\
\hline & Impounding period & 0.51 & 1.85 & 0.72 & 0.27 & \\
\hline
\end{tabular}

Note: $F_{s}$ is the dam slope safety factor of stability under normal operating conditions.

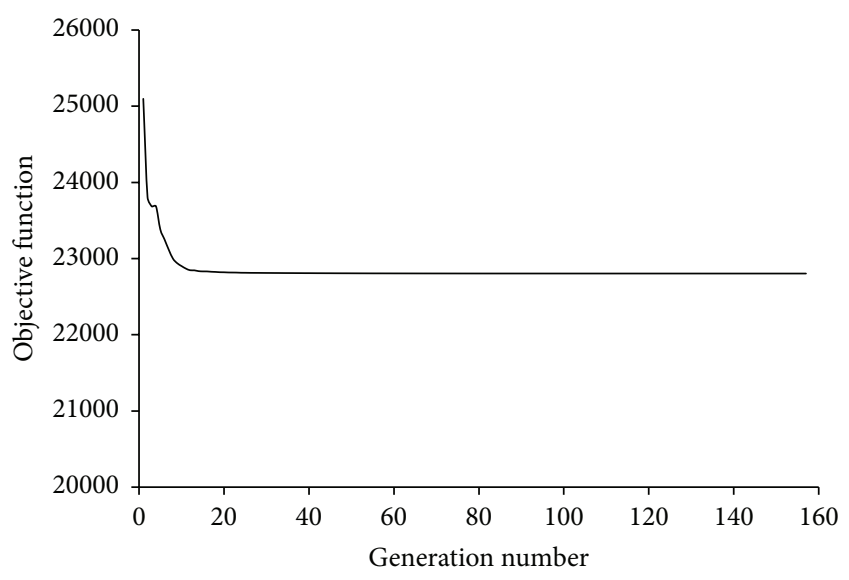

FIGURE 4: Evolution of objective function along generation number.

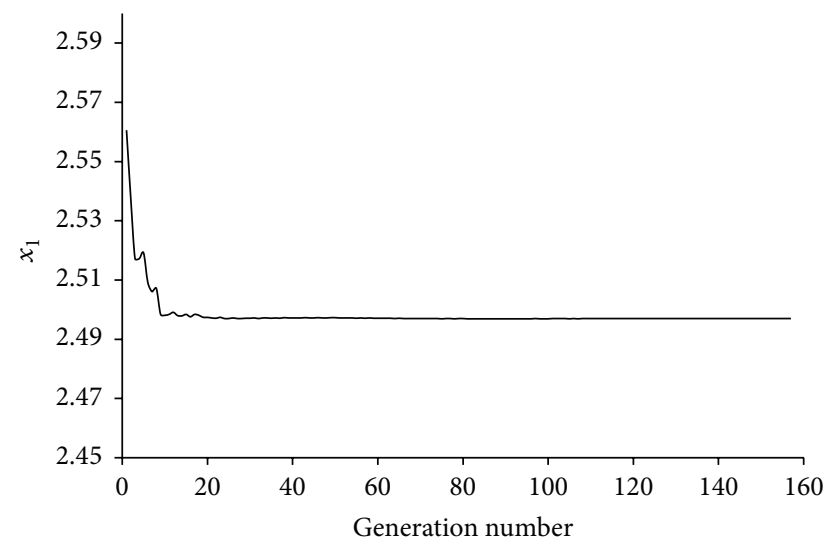

FIgURE 5: Evolution of $x_{1}$ along generation number.

and then the speed of rise is reduced and gradually comes to stability with increase in the top 15 generation numbers in Figures 6 and 7.

5.3.2. Stress Deformation Analysis of the Dam. Table 3 shows the results, optimum solution, optimal value, and main condition index of the genetic optimization algorithm.

(1) Results and Analysis of the Displacement Calculation. The vertical displacements of the dam during completion and impoundment periods are reflected in Figures 8 and 9, respectively.

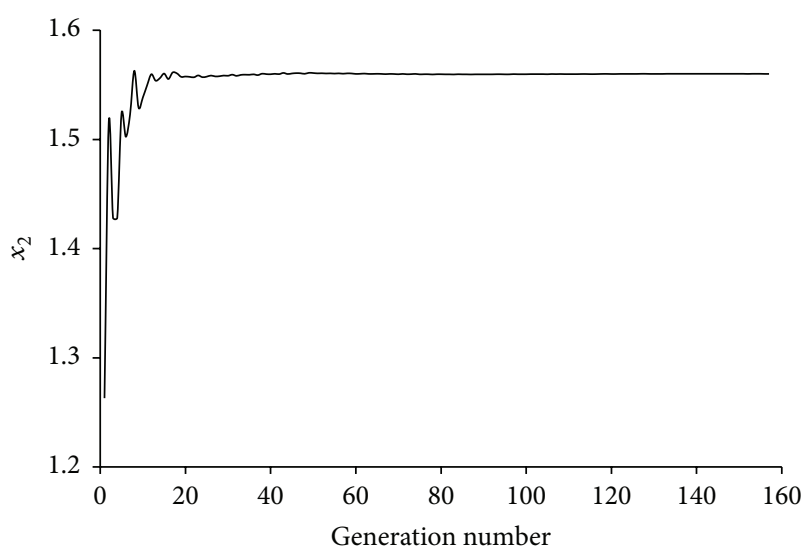

FIGURE 6: Evolution of $x_{2}$ along generation number.

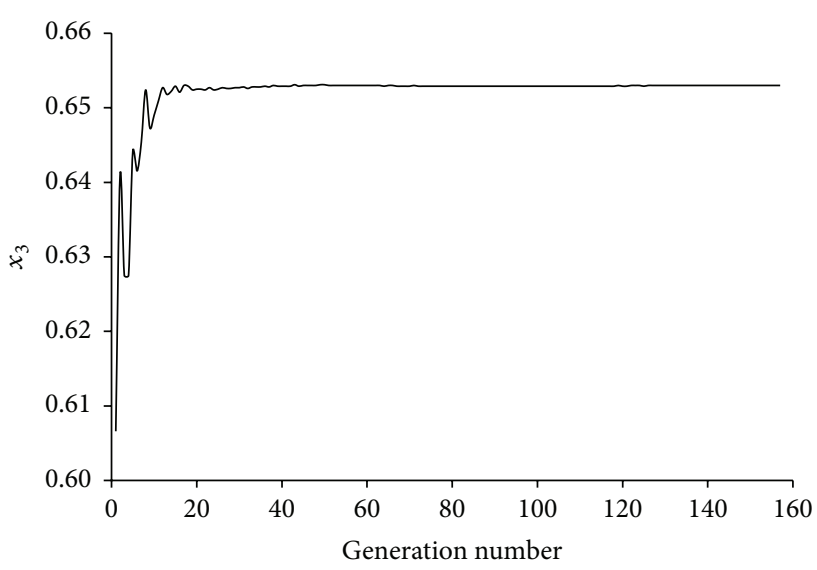

FIgURE 7: Evolution of $x_{3}$ along generation number.

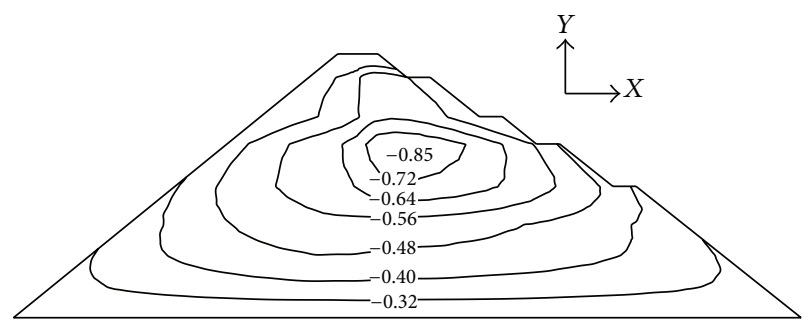

FIgure 8: Contour map of the vertical displacement during the completion period (unit: $\mathrm{m}$ ). 


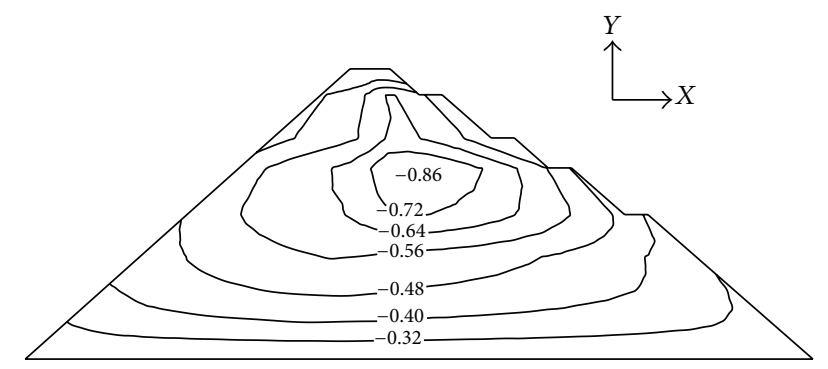

FIgURE 9: Contour map of the vertical displacement during the impoundment period (unit: $\mathrm{m}$ ).

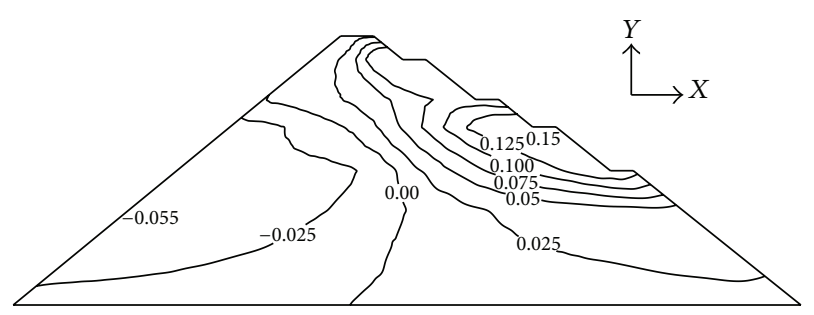

FIGURE 10: Contour map of the horizontal displacement during the completion period (unit: $\mathrm{m}$ ).

After optimization, the largest settlement of the dam during the completion period was $0.85 \mathrm{~m}$, which accounts for about $0.85 \%$ of the dam height and occurs in about two-thirds of the dam height. Given that the downstream rock-fill of the dam is relatively weak, the settlement of the dam displacement is biased toward the dam downstream, and the location of the maximum settlement of the dam was in the secondary rock-fill zone. Consequently, the displacement of the dam crest was slightly biased toward the dam downstream. The dam mainly bears dead weight during the completion period. The area of the dam section decreased after optimization, and the dead weight was reduced. Thus, the dam settlement decreased slightly after the completion period compared with that before optimization.

Compared with the completion period, the impoundment period bore water load and the dam settlement increased slightly. In addition, the maximum settlement during the impoundment period was $0.86 \mathrm{~m}$, which accounts for about $0.86 \%$ of the dam height. The maximum settlement increased about $0.01 \%$ compared with that of the completion period. The maximum settlement occurred in about twothirds of the dam height, which is biased toward the dam downstream. Compared with the design before optimization, the dam settlement decreased slightly during the impoundment period.

The horizontal displacements of the dam during the completion and impoundment periods are shown in Figures 10 and 11, respectively.

During the completion period, the dam is mainly under the action of dead weight load, the horizontal displacement is not symmetrically distributed, and the upstream part of the dam tends to be displaced upstream. In addition, the maximum value of the displacement is $0.055 \mathrm{~m}$, which

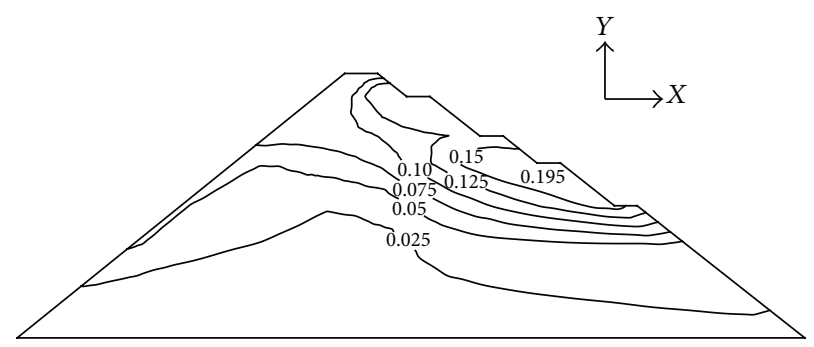

FIGURE 11: Contour map of the horizontal displacement during the impoundment period (unit: $\mathrm{m}$ ).

occurred in one-third of the dam height near the upstream face. The downstream part of the dam tends to be displaced upstream. The maximum value of displacement is $0.15 \mathrm{~m}$, which occurred in one-half of the dam height near the downstream surface. The tendency of displacement during the impoundment period is the same as that during the completion period. However, under the combined actions of water load and dead weight load, the distribution of dam horizontal displacement significantly changed; the zone of the horizontal displacement directing to the upstream side of the dam was significantly reduced, and the maximum horizontal displacement was reduced to $0.00 \mathrm{~m}$. Moreover, the horizontal displacement directing to the downstream increased, and the maximum horizontal displacement increased to $0.195 \mathrm{~m}$, which is located in one-half of the dam height near the downstream surface.

Compared with the design before optimization, the displacement trends of the dam during the completion and storage periods are the same, but the horizontal upstream and downstream displacement significantly changed. During the completion period, the horizontal upstream displacement of the dam increased to $1.68 \mathrm{~cm}$, whereas the horizontal downstream displacement of the dam increased to $7.8 \mathrm{~cm}$. During the impounding period, the horizontal upstream displacement of the dam increased to $0.78 \mathrm{~cm}$, whereas the horizontal downstream displacement of the dam increased to $7.98 \mathrm{~cm}$. This result is mainly caused by the increase in the proportion of downstream rock-fill in the section after optimization. The relatively weak downstream rock-fill of the dam also caused this increase in horizontal displacement.

(2) Results and Analysis of the Stress Calculation. The major principal stress isoline, minor principal stress isoline, and stress level isoline during the completion and impoundment periods are shown in Figures 12-17.

During the completion period, the maximum major principal stress is $1.70 \mathrm{MPa}$ and the maximum minor principal stress is $0.43 \mathrm{MPa}$, in which both stresses are located in the dam base and are near the dam axis. Both stresses are compressive. The directions of the major and minor principal stresses are close to that of gravity. The vertical stress component is close to the dead weight stress of the overlying rock-fill. The stress level of the entire dam is less than 1.0, and the maximum value is 0.65 .

During the impoundment period, the dam stress is redistributed, the dam is under the combined action of 


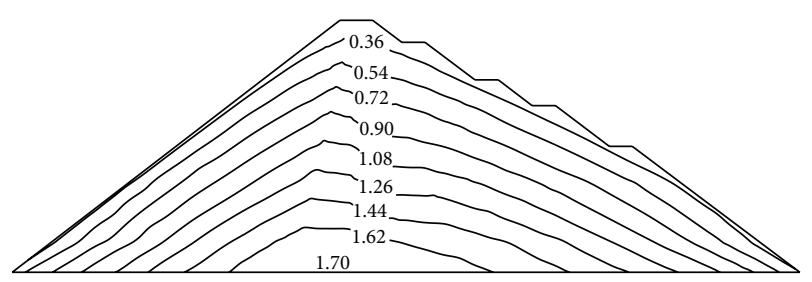

FIGURE 12: Major principal stress isoline during the completion period (unit: $\mathrm{MPa}$ ).

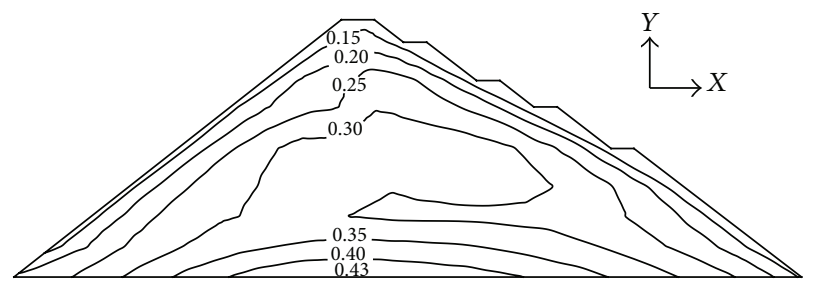

FIGURE 13: Minor principal stress isoline during the completion period (unit: $\mathrm{MPa}$ ).

the dead weight load and water load, the dam stress in the upstream side of the dam axis is more than that in the downstream side, and the dam stress level is less than that of the completion period, in which the maximum value was 0.63 . This result shows that impounding is favorable for the stability of the concrete face rock-fill dam. The water load near the cushion material is perpendicular to the panel and close to the direction of the minor principal stress in the dead weight stress field. The increment of the minor principal stress is greater than that of the major principal stress. This phenomenon results in directional changes of the principal stress. During the impoundment period, the maximum major principal stress is $1.82 \mathrm{MPa}$ and the maximum minor principal stress is $0.51 \mathrm{MPa}$. Both stresses are located in the dam base and are near the dam axis. The dam stress during the impoundment period did not significantly change. The dam stress is mainly caused by the dead weight of the rock-fills, and the dam stress generated by the reservoir water pressure is relatively small. The stress level of the entire dam is less than 1.0 .

Compared with the initial design, the major and minor principal stresses of the dam after the completion period did not significantly change. The major principal stress increased to $0.02 \mathrm{MPa}$, whereas the minor principal stress increased to $0.06 \mathrm{MPa}$. After the impoundment period, the major principal stress decreased to $0.03 \mathrm{MPa}$, whereas the minor principal stress increased to $0.09 \mathrm{MPa}$. The stress level increased to 0.02 in the completion period and increased to 0.05 in the impoundment period. The stress level in most parts of the dam was low. Thus, the dam optimal design with the GA is in good working condition.

(3) Calculation Results of the Panel Deflection and Analysis. The deflection curves of the panel during the completion and impoundment periods are shown in Figures 18 and 19, respectively.

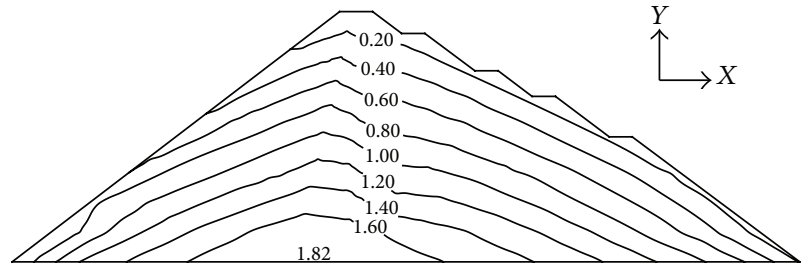

FIGURE 14: Major principal stress isoline during the impoundment period (unit: $\mathrm{MPa}$ ).

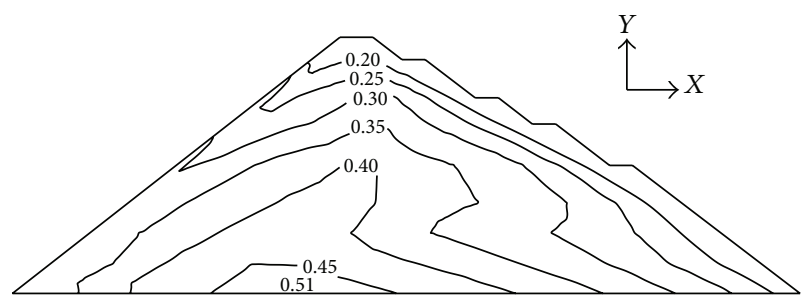

FIGURE 15: Minor principal stress isoline during the impoundment period (unit: $\mathrm{MPa}$ ).

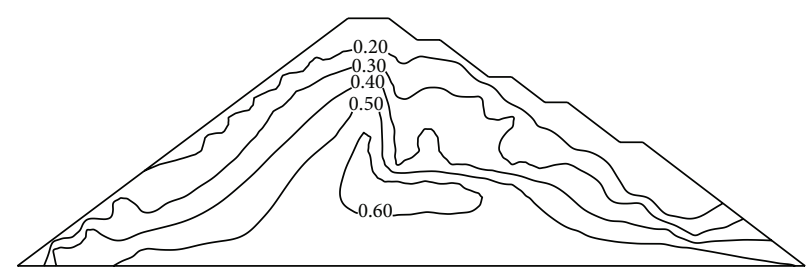

FIGURE 16: Stress level isoline during the completion period.

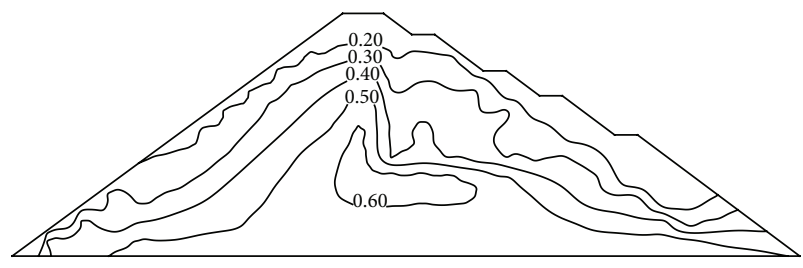

FIgURE 17: Stress level isoline during the impoundment period.

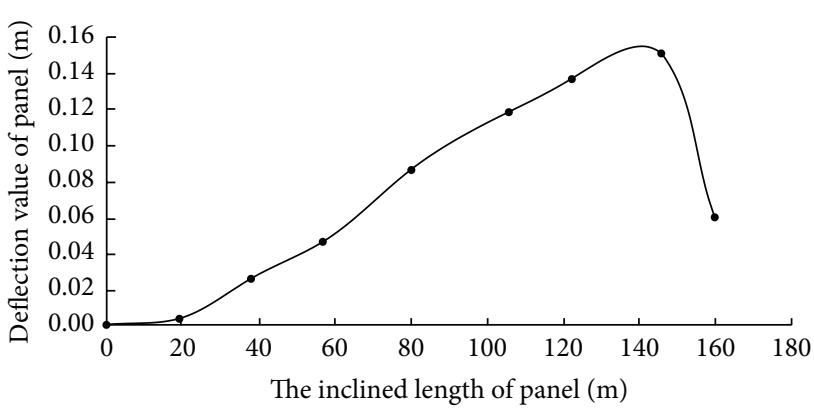

FIGURE 18: Deflection curves of a panel during the completion period. 


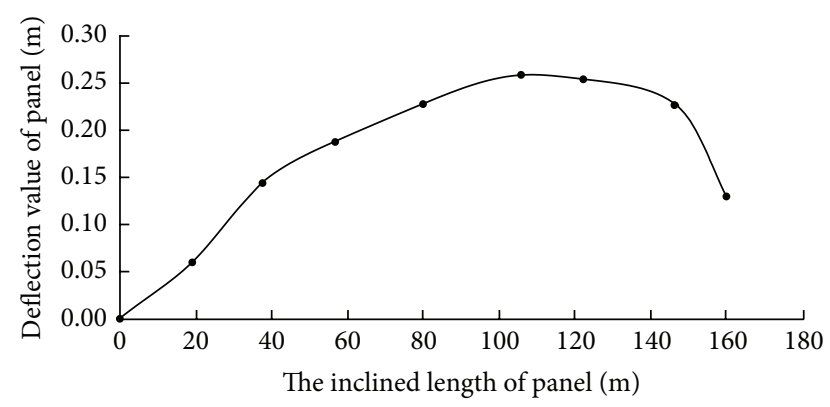

Figure 19: Deflection curves of a panel during the impoundment period. 19.

The following can be seen from Table 3 and Figures 18 and

The maximum deflection of the panel during the completion period is $15.59 \mathrm{~cm}$, which is located in the upper part of the panel. In the impoundment period, the maximum deflection of the panel increased to $26.71 \mathrm{~cm}$ under the effect of the upstream water pressure. The entire panel deformed downstream, and the maximum deflection was located in the middle of the panel, which gradually decreases in the upper and lower parts of the panel. Analysis results show that the panel deflection of the Jishixia project is relatively small, which could not trigger the peripheral joints to produce large displacement and can meet the requirements of the design.

Compared with the initial design, the deflection of the panel increased after optimization. The deflection of the panel increased to $4.34 \mathrm{~cm}$ in the completion period and increased to $4.48 \mathrm{~cm}$ in the impoundment period.

\section{Conclusion}

We conclude the following:

(1) We improved GA with the adaptive principle; by using the improved GA optimization program to conduct the optimal design of Jishixia CFRD, we have determined that the GA could not only solve the global optimal solution problem of complex optimization design, such as the high degree of nonlinearity and the recessiveness of constraint conditions, but also make up for deficiencies which exist in the basic genetic algorithm, such as the weak local searching ability, the nonhigh optimization accuracy, and premature convergence. The GA consumes less time and has high efficiency.

(2) The comparative analysis results between the initial design and optimization show that, after optimization, the dam slope became steeper, the downstream rock-fill area increased, and the quantities of projects and project costs were reduced.

(3) This paper conducts a finite element calculation of stress deformation and dam slope stability on Jishixia CFRD. Results show that, after optimization, both the dam stability and stress deformation conform with the general rule of CFRD, and the maximum stresses meet the requirements. These results confirm that the optimal result is safe, reliable, economic, and reasonable.

\section{Competing Interests}

The authors declare that they have no competing interests.

\section{Acknowledgments}

This research is financially supported by the CRSRI Open Research Program (Program SN: CKWV2014208/KY), the National Natural Science Foundation of China (nos. 51309190, 51409206, and 51579207), Program 2013KCT-15 for Shaanxi Provincial Key Innovative Research Team, China Postdoctoral Science Foundation (no. 2014M552470), Open Research Fund Program of State Key Laboratory of Water Resources and Hydropower Engineering Science (2014SGG03), and the Innovative Research Team of Institute of Water Resources and Hydroelectric Engineering, Xian University of Technology.

\section{References}

[1] M. Zhou and S. Sun, Genetic Algorithms: Theory and Applications, National Defense Industry Press, Beijing, China, 1999.

[2] C. Xin, Structure Analysis and Optimization Design of ConcreteFaced Rock-Fill Dam, China Water Power Press, Beijing, China, 2005.

[3] J. H. Holland, Adaptation in Natural and Artificial Systems, University of Michigan Press, Ann Arbor, Mich, USA, 1975.

[4] D. H. Ackley, A Connectionist Machine for Genetic Hillclimbing, Kluwer Academic Publishers, Boston, Mass, USA, 1987.

[5] D. Whitley, K. Mathias, and P. Fitzhorn, "Delta coding: an iterative search strategy for genetic algorithms," in Proceedings of the 4th International Conference on Genetic Algorithms, pp. 77-84, San Diego, Calif, USA, 1991.

[6] J. Dzubera and D. Whitley, "Advanced correlation analysis of operators for the traveling salesman problem," in Parallel Problem Solving from Nature-PPSN III: International Conference on Evolutionary Computation The Third Conference on Parallel Problem Solving from Nature Jerusalem, Israel, October 9-14, 1994 Proceedings, vol. 866 of Lecture Notes in Computer Science, pp. 68-77, Springer, Berlin, Germany, 1994.

[7] H. Bersini and G. Seront, "In search of a good evolutionoptimization crossover," in Proceedings of the 2nd Conference on Parallel Problem Solving from Nature, pp. 479-488, North Holland, Amsterdam, Netherlands, 1992.

[8] X.-M. Dai, Z.-G. Chen, R. Feng, X.-F. Mao, and H.-H. Shao, "Improved algorithm of pattern extraction based mutation approach to genetic algorithm," Journal of Shanghai Jiaotong University, vol. 36, no. 8, pp. 1158-1160, 2002.

[9] H.-L. Zhao, X.-H. Pang, and Z.-M. Wu, "A building block coded parallel genetic algorithm and its application in TSP," Journal of Shanghai Jiaotong University, vol. 38, no. 2, pp. 213-217, 2004.

[10] L. Jiang, "Study of elastic TSP based on parallel genetic algorithm," Microelectronics, vol. 22, no. 8, pp. 130-133, 2005.

[11] L. Zhang, Y. Liu, B. Li, G. Zhang, and S. Zhang, "Study on real-time simulation analysis and inverse analysis system for temperature and stress of concrete dam," Mathematical 
Problems in Engineering, vol. 2015, Article ID 306165, 8 pages, 2015.

[12] H. Gu, Z. Wu, X. Huang, and J. Song, "Zoning modulus inversion method for concrete dams based on chaos genetic optimization algorithm," Mathematical Problems in Engineering, vol. 2015, Article ID 817241, 9 pages, 2015.

[13] Z. Li, C. Gu, and Z. Wu, "Nonparametric change point diagnosis method of concrete dam crack behavior abnormality," Mathematical Problems in Engineering, vol. 2013, Article ID 969021, 13 pages, 2013.

[14] M. Rezaiee-Pajand and F. H. Tavakoli, "Crack detection in concrete gravity dams using a genetic algorithm," Proceedings of the Institution of Civil Engineers: Structures and Buildings, vol. 168, no. 3, pp. 192-209, 2015.

[15] X. Zongben and L. Guo, "The simulated-biology-like algorithms for global optimization, part I: simulated evolutionary aslgorithms," Chinese Journal of Operations Research, vol. 14, no. 2, pp. 1-13, 1995.

[16] D. B. Fogel, "Introduction to simulated evolutionary optimization," IEEE Transactions on Neural Networks, vol. 5, no. 1, pp. 3-14, 1994.

[17] D. E. Goldberg and P. Segrest, "Finite Markov chain analysis of genetic algorithms," in Proceedings of the 2nd International Conference on Genetic Algorithms, pp. 1-8, Cambridge, Mass, USA, July 1987.

[18] H. Asoh and H. Mühlenbein, "On the mean convergence time of evolutionary algorithms without selection and mutation," in Parallel Problem Solving from Nature-PPSN III, vol. 866 of Lecture Notes in Computer Science, pp. 88-97, Springer, Berlin, Germany, 1994.

[19] C. A. Ankenbrandt, "An extension to the theory of convergence and a proof the time complexity of genetic algorithms," Foundations of Genetic Algorithms, pp. 53-58, 1990.

[20] G. Xuejing and W. Pu, "An adaptive genetic algorithm based on real coded and its application," Journal of Beijing University of Technology, vol. 33, no. 2, pp. 144-148, 2007. 


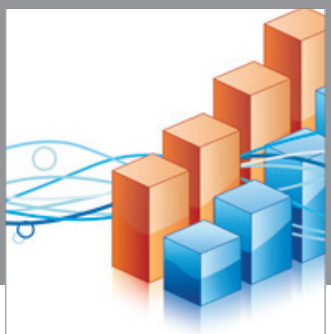

Advances in

Operations Research

vatem alat4

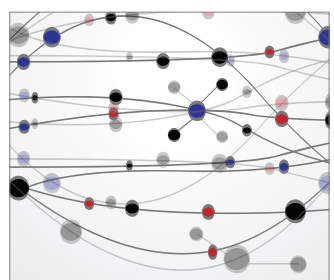

\section{The Scientific} World Journal
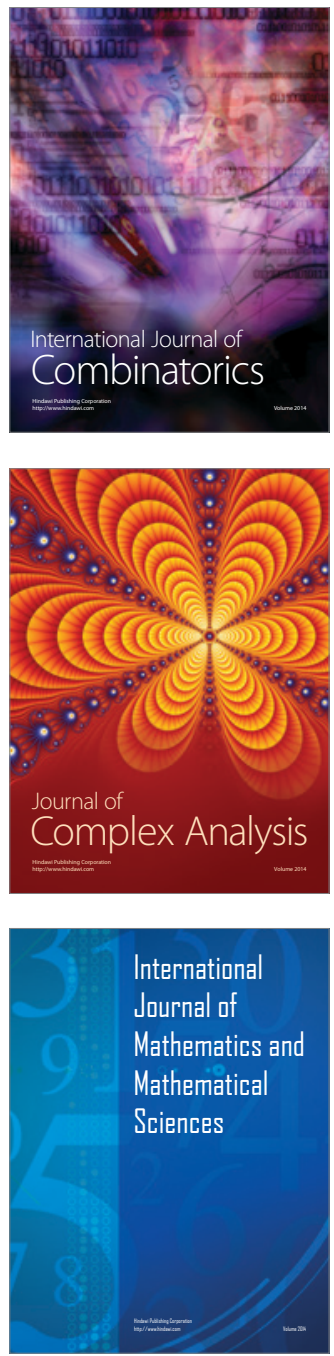
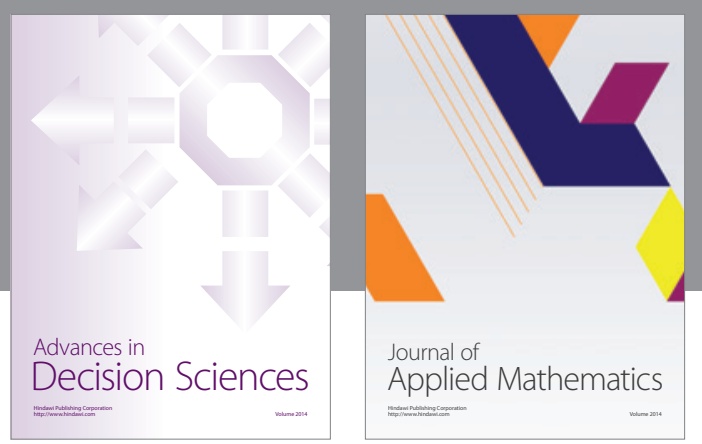

Algebra

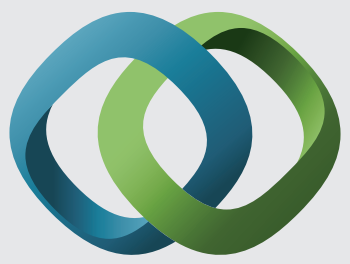

\section{Hindawi}

Submit your manuscripts at

http://www.hindawi.com
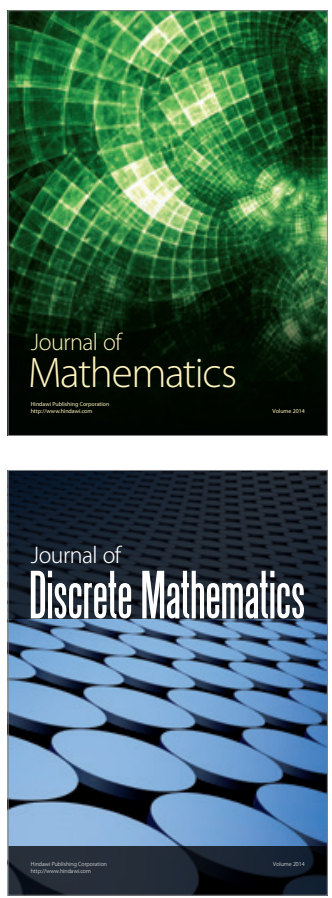

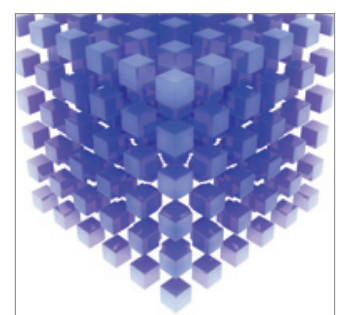

Mathematical Problems in Engineering
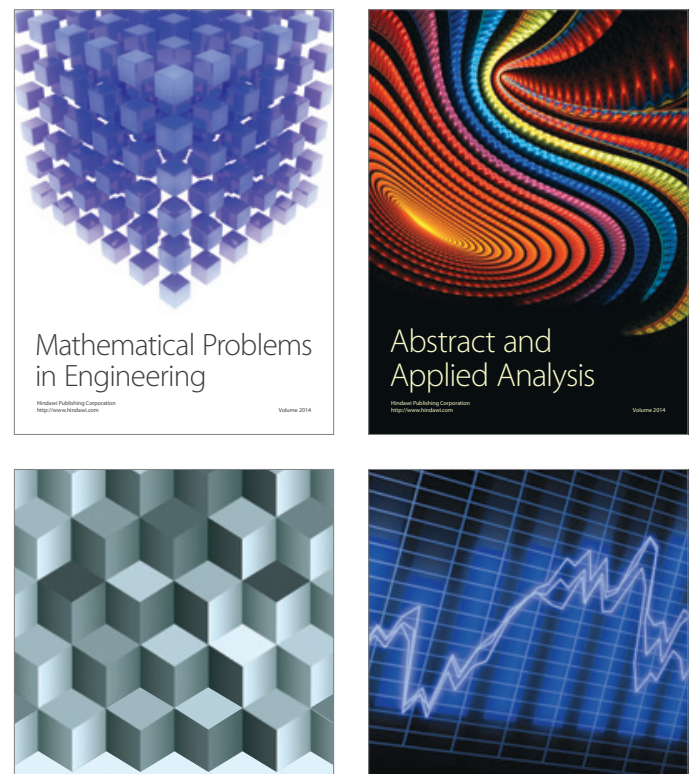

Journal of

Function Spaces

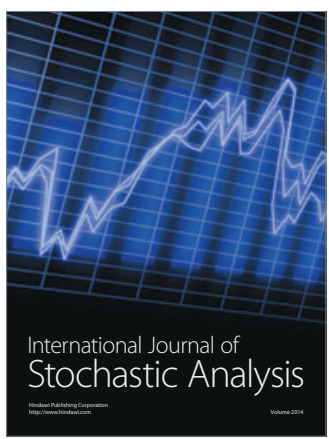

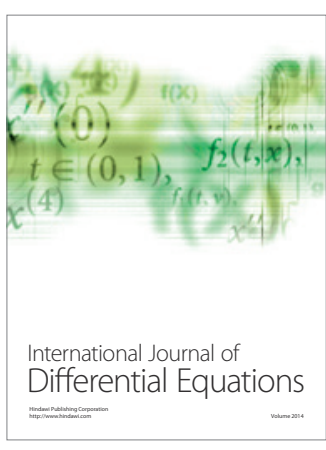
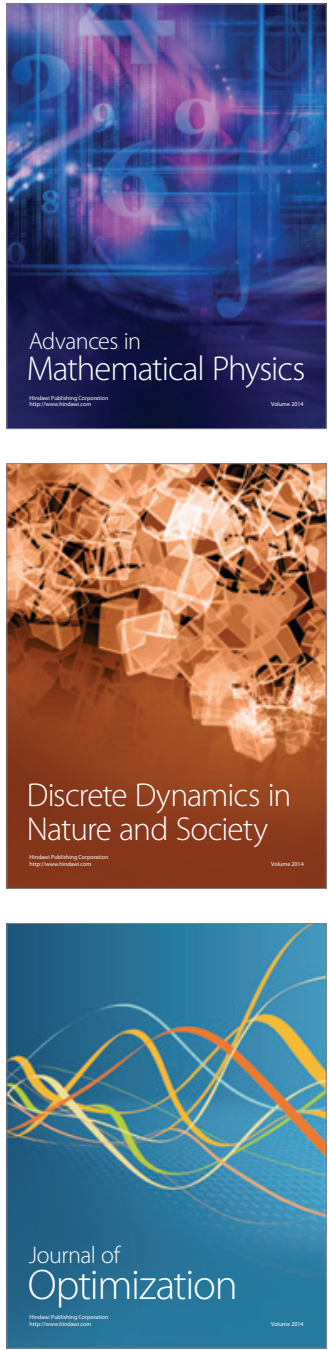